11 Anderson HR. Is the prevalence of asthma changing? Arch Dis (ihld 1989:64:172-5

12 Hill RA. Standen PJ, Tattersficld AE. Asthma, whecring and school absence in primary schools. Arch Dis (hild 1989;64:246-51.

13 Dodge RR, Burrows B. The prevalence and incidence of asthma and asthma-like symptoms in a general population sample. Am Rev Respir $D t_{l}$ $1980 ; 122: 567-75$

It Jackson RT, Beaglehole R, Rea HH, Sutherland DC. Mortality from asthma: a new epidemic in New Zealand. Br.Med f 1982:285:771-4.

15 Bousquet J. Hatton F, Godard P. Michel FB. Asthma mortality in France. 7 Allergy Clin Immunol 1987:80:389-94.

16 Evans $R$. Recent advances reflecting increases in mortality from asthme. 7 Allergy Clin Immunol 1987:80:377-9.

17 Mitchell EA, Cutler DR. Paediatric admission to Auckland Hospital for asthma 1970-80. NZ Med f 1984:97:67-70.

18 Halfon $N$, Newacheck $P W$. Trends in the hospitalisation for acute childhood asthma. Am 7 Public Health 1986;76:1308-11.

19 Chinn S, Rona RJ. The secular trend in the height of primary school children in England and Scotland from 1972-80. Ann Hum Biol 1984:11:1-16.

20 Woolson RF, Clarke WR. Analysis of categorical incomplete longitudinal data. Fournal of the Royal Statistical Society 1984;147A:87-99.

21 SAS Institute. S.AS users' guide: statistics. Version 5 edition. Cary, North Carolina: SAS Institute, 1985:171-253.

22 Armitage P, Berry G. Statistical methods in medical research. 2nd ed. Oxford: Blackwell Scientific, 1987:386-99.

23 Rona RJ, Altman DG. National study of health and growth: studies of attained height, weight and triceps skinfold in English children 5 to 11 years old. Ann Hum Biol 1977:4:501-23.

24 Chinn S, Rona RJ, Price CE. The secular trend in height of primary scheol children in England and Scotland 1972-1979 and 1979 to 1986. Ann Hum Biol 1989:16:387-95

25 Speight ANP, Lee DA, Hey EN. Lnderdiagnosis and undertreatment of asthma in childhood. Br. Med f 1983:286:1253-6.

26 Anderson HR, Bailey PA, Cooper JS, Palmer JC, West S. Medical care of asthma and wheezing illness in children: a community survey. 7 lipidemol Community Heulth 1983:37:180-6.

27 Mitchell FA. Is current treatment increasing asthma mortality and morbidity? Thorax 1989:44:81-4.

28 Van Weel C, van den Bosch WJHM, van den Hoogen HLM. Smits AJA Development of respiratory illness in childhood - a longitudinal study in general practice. $7 R$ Coll Gen Pract 1987:37:004-8.

29 Giles GG, Gibson HB, Lickiss N, Shaw K. Respiratory svmptoms in Tasmanian adolescents: a follow up of the 1961 birth cohort. A ust $N \% 7$. . Hed $1984 ; 14: 631-7$.

30 Taylor B, Wadsworth J, Wadsworth M, Peckham C. Changes in the reported prevalence of childhood eczema since the 1939-45 war. Lancet $1984 ;$;i: $1255-7$

31 Magnusson CG. Maternal smoking influences cord serum IgE and IgI) levels and increases the risk for subsequent infant allergy: F Allergy C/m Immunol 1986;78:898-9014.

32 Ware JH, Dockery DW, Spiro FE, Ferris BG. Passive smoking, gas cooking. and respiratory health of children living in six cities. Am Rec Respir Dis 1984:129:366-74.

33 Strachan ID. Hay fever, hygiene, and houschold size. Br. Med $\mathcal{f}$ 1989;299: $1259-60$

Accepted 8.March 1990
Department of Minimally Invasive Surgery, London Clinic, London W1N 2DH S G Chiverton, FRCS, lecturer $\mathrm{J}$ A Inglis, FRCS, lecturer C Hudd, FRCS, lecturer M J Kellett, FRCR, consultan radiologist

J E A Wickham, FRCS academic unit director

Middlesex Hospital, London W1P 7PN

R C G Russell, FRCS, consultant surgeon

Correspondence to: Mr Wickham.

\title{
Percutaneous cholecystolithotomy: the first 60 patients
}

\author{
S G Chiverton, J A Inglis, C Hudd, M J Kellett, R C G Russell, J E A Wickham
}

\begin{abstract}
Objective-To assess the feasibility and possible complications of percutaneous removal of gall stones.

Design-Prospective study of the first 60 patients treated.

Setting-The London Clinic.

Patients - 60 Consecutive patients with symptomatic gall stones who agreed to have them removed percutaneously.

Results-56 Patients had stones successfully removed percutaneously. In four patients failure of access necessitated a cholecystectomy under the same anaesthetic. Two patients had an empyema of the gall bladder drained initially, followed by a second operation to remove the stones one week later. Seven patients had postoperative complications, and two had recurrences of biliary calculi.

Conclusions-The techniques and instruments used in percutaneous nephrolithotomy can successfully be adapted for percutaneous removal of gall stones. The procedure is suitable for a wider range of patients than other techniques that leave the gall bladder intact.
\end{abstract}

\section{Introduction}

Percutaneous nephrolithotomy and extracorporeal shock wave lithotripsy have now virtually replaced open renal surgery. We decided to use the method entailed in percutaneous nephrolithotomy to remove calculi from the gall bladder. Other techniques are available to clear biliary calculi, but they have certain disadvantages. Extracorporeal shock wave lithotripsy and dissolution treatment both require the gall bladder to be functioning and are restricted to particular types of stones, and with both procedures the calculi take a considerable time to clear..$^{1-4}$ Dissolution of calculi with methyl tert-butyl ether requires percutaneous access and is also time consuming. Percutaneous cholecystolithotomy allows stones to be completely removed immediately and does not need a functioning gall bladder. We have previously reported our initial experience of the technique ${ }^{b}$ and now report on our first 60 patients.

\section{Patients and methods}

From November 1986 to September 1989 we selected 29 men and 31 women aged 25-74 (mean age 51) for treatment. All had symptomatic gall stones. Initially, we selected only patients whose gall bladder was functioning, but later we included patients whose gall bladders were not functioning if this was thought to be due to a stone obstructing Hartmann's pouch. None of the patients had any other medical conditions, and all elected to have percutaneous cholecystolithotomy after the alternatives had been explained. Each patient agreed to have an immediate cholecystectomy under the same anaesthetic if the procedure could not be completed satisfactorily. We assessed the gall bladder by oral cholecystography and ultrasonography, ultrasonography being used to determine its accessibility and the line of approach needed for the percutaneous track. Six hours before the operation each patient was given oral contrast medium (calcium ipodate $6 \mathrm{~g}$ ) to aid fluoroscopic localisation of the gall bladder. Prophylactic antibiotics were given when the patients were anaesthetised.

\section{TECHNIQUE}

We anaesthetised patients on a fluoroscopic table and placed drapes to collect the irrigant, as for percutaneous nephrolithotomy. The gall bladder was localised by both ultrasonography and fluoroscopy and punctured, usually subcostally, with a $152 \mathrm{~mm}$ long dwell sheathed needle (Becton Dickinson, Ontario, Canada). A guidewire was introduced through the sheath and a 7 Charrière gauge pigtail catheter (Cook Urological, Letchworth) advanced into the gall bladder to aspirate the bile and minimise any ieakage. The gall bladder was then filled with dilute contrast medium and the tract dilated up to 28 Charrière gauge with graduated metal dilators (Olympus, Keymed, Southend on Sea) under fluoroscopic control. Finally, an Amplatz sheath was inserted and the metal dilators removed, leaving the guidewire in place. Care was taken not to cause invagination of the gall bladder wall during the dilatation.

We used an 18 French gauge nephroscope (Richard Wolf, Mitcham, Surrey) to visualise the lumen of the gall bladder. Small stones were removed 
intact with various grabbing forceps. Larger stones were fragmented by ultrasound, electrohydraulic lithotripsy, or a pulse dye laser (Candela, Boston, Massachusetts), fragments being aspirated or removed with forceps. When all the stones were judged to have been removed a Foley catheter was inserted down the Amplatz sheath, the balloon inflated, and contrast medium injected to fill the gall bladder. The gall bladder was then examined by fluoroscopy and spot films, and any residual fragments were removed. In the first patients drainage was continued with the Foley catheter, but later a self retaining pigtail catheter (Cook Urological) was used. The catheter was allowed to drain freely for the first two days and then sealed with a spigot but left in place for 10 days so that a tract could mature. If imaging of dye injected down the tube then showed a free flow of contrast into the duodenum and no extravasation or evidence of residual calculi the tube was removed.

\section{Results}

Failure of access occurred in four of the 60 patients; all four patients had a successful uncomplicated cholecystectomy under the same anaesthetic. Two patients had empyema of the gall bladder at the time of percutaneous cholecystolithotomy and therefore had their gall bladders drained and a second operation to remove the stones one week later; this was successful in both cases and not associated with additional morbidity. Seventeen patients had more than three stones, and we were able to remove all these stones intact with alligator forceps. The largest number of stones in one gall bladder was 135 . Twenty five patients required lithotripsy to fragment the stones: four had ultrasound alone, 13 electrohydraulic lithotripsy, and two a combination of ultrasound and electrohydraulic lithotripsy; six patients had stones broken by a pulse dye laser. When ultrasound was used aspiration took place at the same time as fragmentation; in the remaining cases stones were fragmented into sufficiently large pieces to permit their removal with forceps.

Seven patients had postoperative complications. Two patients had leakage of bile postoperatively. In one the tube became dislodged from the gall bladder, causing a subphrenic accumulation, which was successfully drained by needle aspiration. In the other, access to the gall bladder was lost after the calculi were removed and leakage occurred, although a peritoneal drain had been apparently successful for two days; the leak was controlled by puncturing the gall bladder under local anaesthesia and inserting a pigtail catheter, which was removed without complication one week later. In one patient an undetected colonic puncture occurred during cholecystolithotomy, which produced a localised faecal leak and fistula; this closed spontaneously during intravenous alimentation over 10 days. One patient had a mild attack of pancreatitis, which was managed conservatively. Two patients still had stones after the operation: one had a stone in the common bile duct that had not been noticed before the operation and had endoscopic retrograde cholangiopancreatography three days after the cholecystolithotomy. The other had a stone in Hartmann's pouch and required a second cholecystolithotomy a month later. One patient had a respiratory arrest due to a previously unrecognised myasthenic syndrome and was successfully treated. None of the patients died within 30 days of the operation, although one died from an unrelated myocardial infarct at four months.

At follow up three months after the operation no patient had a recurrence of stones and only one patient had unresolved symptoms. Two patients presented with further symptoms and stones at the six month follow up. We followed up 39 patients for longer than six months: 18 were reassessed by ultrasonography (mean follow up 17.5 months; range 9-36 months), and no further recurrences were detected.

\section{Discussion}

Less invasive methods of surgical management are now available for various disorders. This is particularly true in urology in which transurethral resection of the prostate and percutaneous nephrolithotomy have almost totally replaced open operations. The technique and safety of percutaneous nephrolithotomy have been well established, and we successfully adapted the technique to percutaneous cholecystolithotomy.

The gall bladder presents different difficulties from those presented by the kidney. Because the gall bladder is more mobile and contained in the peritoneal cavity it can be difficult to puncture, either moving away or invaginating during dilatation of the tract. Failure of access occurred in four patients, all of whom were among the first 30 treated. We later found that invagination could be prevented by ensuring that the early stages of dilatation were carried out thoroughly. In the kidney, however, there can be an immediate jump to an 8 Charrière gauge dilator. Bile irritates the peritoneal cavity and care must therefore be taken to ensure that spillage is kept to a minimum. We initially aspirated bile through a pigtail catheter at the start of dilatation of the tract but stopped this procedure as we became more confident. The patients whose bile was not aspirated seemed to experience more postoperative discomfort and needed more analgesia so we have now resumed aspiration.

Closing the drainage catheter with a spigot two days after the operation sometimes caused patients pain, which was often due to impaction of the tip of the Foley catheter in the entrance of the cystic duct and the balloon in Hartmann's pouch. Replacing the tube with a self retaining pigtail catheter resolved this problem.

Though cholecystolithotomy removes the stones from the gall bladder, it has the same potential disadvantage as other techniques in which the gall bladder is left in situ-namely, that of recurrence of stones. At present only limited data are available on recurrence rates after dissolution treatment, although this treatment is the best documented; a recurrence rate of $12.5 \%$ in the first year after dissolution rising to $61 \%$ after 11 years has been reported. ${ }^{8} \mathrm{~A}$ high recurrence rate was also associated with open cholecystolithotomy, and this, together with all the disadvantages of open surgery, has made the procedure unpopular." "As yet insufficient follow up data are available on either extracorporeal shock wave lithotropy or dissolution with methyl tert-butyl ether, but similar rates might be expected. Patients may be prone to forming stones for many reasons ${ }^{11}$; among them a defect in motility is well documented. ${ }^{12}$ At present we have evidence of only two possible recurrences of biliary calculi among our patients.

We have shown the practicality of a less invasive method of removing biliary calculi that can complement both extracorporeal shock wave lithotripsy and cholecystectomy. Properly controlled trials of drugs that prevent recurrence of gall stones must now be carried out.

\footnotetext{
1 Sauerbruch T, Delius M, Paumgartner G, et al. Fragmentation of gallstones by extracorporeal shock waves. N Engl f. Med 1986;314:818-22.

Sackman M, Delius M, Sauerbruch T, et al. Shockwave lithotripsy of gallbladder stones. The first 175 patients. N Engl Y Med 1988:318:393-7.

3 Podda $M$, Zuin M, Battezzati PM, (Ghezzi C, de Fazio C, Dinguardi MI. Efficacy and safety of a combination of chenodeoxycholic and ursodeoxy cholic acid for gallstone dissolution: a comprarison with ursodeoxycholic acid alone. (iustroenterology 1989:96:220-9.

4 Leuschner M, Leuschner U, Lazorvici D, Kurtz W, Hellstern A. Dissolution
} 
of gallstones with an ursodeoxscholic acid-menthol preparation a controlled prospective double hlind trial. Gut 1988:92:+28 -32.

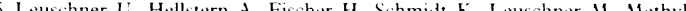
tert-hutyl ether for gallstone dissolution, clinical results and toxicity.

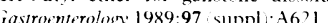

6 Kellett MJ, Wickham JEA, Russell RCG. Percutancous cholecystolithotom BrMed Y 1988:296:453-5.

7 Wickham JEA. Miller RA. Percutaneous renal surgery. London: Churchill Livingstone, 1983

8 Villanova $\mathrm{N}$, Bazzoli $\mathrm{F}$, Taroni $\mathrm{F}$, et al. (Gallstone recurrence after successful oral bile acid treatment. A 12 vear follow up study and evaluation of long term post dissolution treatment. Gasiroenterolugy 1989;97:726-31.
9 Pers $\mathrm{M}$, Baden $\mathrm{H}$. On the frequency of recurrence of calculi in the gallbladder fter cholecrstolithotomy tow Chir Siand 1952;102:260-6.

10 Norrby S, Schoncbeck J. Long term results with cholecrstolithotomy tcta Chir Scand 1970;136:711-3.

11 Anonymous. (jallstones, bile acids and the liver [Editorial]. Lance 1989;ii: $249-51$

12 Spengler V, Sackman M, Sauerbruch T, Holl J, Paumgartner G. Gallbladder motility before and after extracorporeal shockwave lithotripsy: Gastroenterologe 1989;96:860-3.

Accepted 22 February 1990

\section{Comparison of vascular tone during combined haemodialysis with ultrafiltration and during ultrafiltration followed by haemodialysis: a possible mechanism for dialysis hypotension}

\section{John R Bradley, David B Evans, Alan J Cowley}

\section{Department of Renal \\ Medicine, Addenbrooke's Hospital, Cambridge CB2 2QQ \\ John R Bradley, MRCP, senior registrar \\ David B Evans, FRCP \\ consultant physician}

Department of Medicine, University Hospital,

\section{Nottingham}

Alan J Cowley, DM, senior lecturer

Correspondence to: Dr Bradley.

Br Med f 1990;300:1312-3
Haemodialysis is frequently complicated by severe and symptomatic hypotension, which is associated with and may be caused by abnormalities of peripheral venous tone.' Hypotension during haemodialysis can, however, be prevented if ultrafiltration is performed separately from dialysis. ${ }^{2}$ If inappropriate changes in peripheral vascular tone are important in the development of dialysis induced hypotension we would expect them not to occur during isolated ultrafiltration. We therefore compared changes in peripheral vascular tone and blood pressure during combined ultrafiltration and haemodialysis with those during sequential ultrafiltration and haemodialysis.

\section{Patients, methods, and results}

Four men and four women (mean age 52 (SD 16)) undergoing long term haemodialysis gave their informed consent, and the local ethical committee approved the study. Patients first received combined acetate haemodialysis and ultrafiltration for four hours, during which fluid was removed at a continuous rate. One week later patients underwent isolated ultrafiltration for one hour followed by acetate dialysis without removal of fluid for four hours. During ultrafiltration the same amount of fluid as had been lost the previous week was removed.

Forearm blood flow and venous tone were measured every 15 minutes during dialysis by venous occlusion plethysmography using mercury in Silastic strain gauges in the arm without the fistula. Venous tone was measured as the increase in volume of the forearm when a venous occlusion cuff was inflated to $40 \mathrm{~mm} \mathrm{Hg}$ around the upper arm causing the venous bed to fill. An increase in the index of venous tone indicated venodilatation. Forearm vascular resistance was calcu-

Mean (SE) rates of change in haemodynamic variables during combined dialysis and ultrafiltration and during ultrafiltration followed by dialysis

\begin{tabular}{|c|c|c|c|}
\hline & \multirow{2}{*}{$\begin{array}{l}\text { Combined haemodialysis } \\
\text { and ultrafiltration }\end{array}$} & \multicolumn{2}{|c|}{$\begin{array}{l}\text { Sequential ultrafiltration and } \\
\text { dialysis }\end{array}$} \\
\hline & & Lltrafiltration & Dialysis \\
\hline Heart rate $($ beats $/ \mathrm{min} / \mathrm{h}$ ) & $2 \cdot 3\left(0 \cdot 43^{\star \star}\right.$ & $0 \cdot 2 \quad 1 \cdot 16$ & $2.4(0.68)$ \\
\hline Mean arterial pressure $(\mathrm{mm} \mathrm{Hg} / \mathrm{h})$ & $-5 \cdot 2(1 \cdot 13 \star \star \star$ & $7 \cdot 6 \quad 2 \cdot 28)$ & $1.7(0.44)$ \\
\hline Forearm venous tone $(\mathrm{ml} / 100 \mathrm{ml}$ over $40 \mathrm{~mm} \mathrm{Hg} / \mathrm{h})$ & $0 \cdot 27(0 \cdot 05)^{\star \star}$ & $0.45(0.09)^{\star}$ & $0 \cdot 33(0 \cdot 06)^{\star \star}$ \\
\hline Forearm vascular resistance (arbitrary units/h) & $1.8(0.51)^{\star}$ & $15 \cdot 8(4.33)^{\star}$ & $5.2(1.73)^{\star \star}$ \\
\hline
\end{tabular}

${ }^{\star} \mathrm{p}<0 \cdot 05 ;{ }^{\star \star} \mathrm{p}<0 \cdot 01$, signed ranks test. lated by dividing mean arterial pressure by forearm blood flow, which was measured by standard techniques. ${ }^{+}$Changes in plasma volume were calculated from changes in the packed cell volume.

To determine the significance of changes in haemodynamic variables the slopes of regression lines of each variable with time during each procedure were calculated for each patient by the least squares method Whether regression slopes differed from zero was tested using the signed rank sum test.

During combined haemodialysis and ultrafiltration for four hours plasma volume fell by 14.5 (SE 1.7)\%. Forearm vascular resistance increased but the forearm venous bed dilated inappropriately and mean arterial blood pressure fell (table). During isolated ultrafiltration for one hour plasma volume fell by $18 \cdot 6(2 \cdot 2) \%$. Forearm vascular resistance increased considerably, the forearm venous bed constricted appropriately, and mean arterial pressure did not change significantly. During subsequent dialysis for four hours plasma volume returned to $90.9(1.9) \%$ of the preultrafiltration level. During this refilling of the vascular bed forearm vascular resistance fell and the forearm venous bed dilated but mean arterial pressure remained stable.

\section{Comment}

One of the main aims of haemodialysis is to remove excess fluid. This is initially achieved by reducing plasma volume, and the integrity of peripheral vascular responses is essential if blood pressure is not to fall. The results of this study suggest that dialysis induced hypotension may be associated with abnormalities of both the arteriolar and venous sides of the circulation. During combined dialysis and ultrafiltration there was a considerable fall in blood pressure associated with only a small increase in forearm vascular resistance and inappropriate dilatation of the venous bed.

These abnormalities of peripheral vascular tone did not occur during isolated ultrafiltration, when the forearm veins constricted and forearm vascular resistance almost doubled. These changes in vascular tone, which are appropriate responses to a reduced plasma volume, may account for the well recognised cardiovascular stability during isolated ultrafiltration."

In the absence of any difference in plasma volume depletion between ultrafiltration alone and in combination with dialysis the different peripheral vascular responses are presumably due to the effects of dialysis. Correction of the metabolic derangements of renal failure probably withdraws a stimulus to vasoconstriction.

1 Bradlev JR, Evans DB, Gore SM. Cowley AJ. Is dialysis hypotension caused by an abnormality of venous tone? Br.Med 7 1988;296: 1634-7.

2 Bergstrom J, Asaba H, Furst P, Oules R. Dialysis, ultrafiltration, and bloos pressure. Proc Liar Dial Transplant dssoc 1976;13:293-305.

Bevegard BS, Shepherd JT. Changes in the tone of limb veins during supine exercise. 7 Appl Physiol 1965:20:1-8.

Greenfield ADII, Whimer. RJ, Mowbray Jl: Methods for the investigation of peripheral bleod flow. Br. Med Bull 1963:19:101-9.

Beuph W ments. F Appl Physiol 1972:32:712-3. 